\title{
RELEVANSI SIMULASI PERMAINAN "HIKAYAT KERBAU AIR" SEBAGAI MEDIA LITERASI PERDAMAIAN BAGI AKTIVIS AISYIYAH
}

\author{
Surwandono', Ali Maksum² \\ 1 Universitas Muhammadiyah Yogyakarta \\ Korespondensi email: surwandono@umy.ac.id \\ ${ }^{2}$ Universitas Muhammadiyah Yogyakarta \\ email: ali.maksum@fisipol.umy.ac.id
}

\begin{abstract}
This article examined the relevance of game simulation as a model for learning literacy for women activists in sosial and religious isues. Women was peace aktors who have a natural peace instinct compared to men, but in the context of sosial conflict, women's involvement in conflict and peace decision making tends to be minimum. The community services method was conducted by the intervention of knowledge and the value of peace by using the simulation game called "Hikayat Kerbau Air" or Water Buffalo. The "Hikayat Kerbau Air" was a game that mobilizes structured experiences that can provide deep scars so that it is expected to be a good stimulus when experiencing similar experiences in the real world. The results of the service interventions showed that the structured experience gained from the "Hikayat Kerbau Air" game simulation increased the emphatic process and sympathy for the competitors without losing the goals to be achieved. Conflict style choices become more moderate and humanist.
\end{abstract}

Keywords: simulation; peace literacy; women activist.

\begin{abstract}
ABSTRAK
Artikel ini menjelaskan tentang relevansi simulasi permainan sebagai model pembelajaran literasi perdamaian bagi kalangan aktivis perempuan dalam isu sosial dan keagamaan. Perempuan merupakan aktor perdamaian yang memiliki insting perdamaian yang alami dibandingkan dengan laki-laki, namun dalam konteks konflik sosial, keterlibatan perempuan dalam pengambilan keputusan konflik dan perdamaian cenderung minimal. Metode pengabdian dilakukan melalui intervensi pengetahuan dan nilai perdamaian dengan menggunakan simulasi permainan "Hikayat Kerbau Air". Permainan "Hikayat Kerbau Air" merupakan permainan yang memobilisasi pengalaman berstruktur yang dapat memberikan bekas yang mendalam sehingga diharapkan akan menjadi stimulus yang baik tatkala mengalami pengalaman serupa dalam dunia nyata. Hasil intervensi pengabdian menunjukan bahwa pengalaman berstruktur yang diperoleh dari simulasi permainan "Hikayat Kerbau Air" meningkatkan proses emphati dan simpati kepada pihak competitor tanpa harus kehilangan tujuan yang hendak dicapai. Pilihan gaya berkonflik menjadi lebih moderat dan humanis.
\end{abstract}

Kata Kunci: simulasi; literasi perdamaian; aktivis perempuan. 


\section{PENDAHULUAN}

Pengabdian ini mempunyai tujuan untuk mempertahankan kultur harmoni dalam menjalankan praktik sosial keagamaan dalam masyarakat di Desa Palbapang Barat Kecamatan Bantul, Kabupaten Bantul Yogyakarta melalui sejumlah aktivitas: Pertama, obyektifikasi terhadap perilaku kehidupan harmoni dalam masyarakat sub-urban dalam konteks sebagai desa percontohan demokrasi. Kedua, eksternalisasi dalam konteks arti penting tata nilai harmoni dalam masyarakat sub-urban yang semakin kompetitif dalam menjalankan praktik demokrasi di desa. Ketiga, melakukan internalisasi tata nilai harmoni sebagai upaya peningkatan kapasitas organisasi keagamaan berbasis sebagai agen sosial dalam penciptaan harmoni sosial dalam masyarakat melalui literasi perdamaian dengan menggunakan model permainan simulasi konflik dan perdamaian "Hikayat Kerbau Air".

Desa Palpabang dipilih sebagai lokasi pengabdian terkait dengan posisi sosial desa Palbapang Barat sebagai desa percontohan dalam praktik demokrasi desa di kabupaten Bantul. Organisasi Aisyiyah merupakan organisasi otonom Muhammadiyah yang memiliki kontribusi besar dalam gerak kehidupan sosial, ekonomi dan keagamaan di masyarakat, yang mengelola 15 Masjid, 2 sekolah dasar dan 3 sekolah Taman Pendidikan Bustanul Atfal. Pimpinan Ranting Aisyiyah Palbapang Barat, juga telah ditunjuk sebagai Ranting Percontohan dalam menjalankan Pedoman Hidup Islami, pada Pimpinan Daerah Aisyiyah Kabupaten Bantul. Untuk mempertahankan diri sebagai desa harmoni dalam sosial keagamaan diperlukan sejumlah perangkat gagasan dan pendampingan agar Pimpinan Ranting Aisyiyah Palpabang Bantul dapat berkontribusi efektif sebagai agen sosial dalam kehidupan sosial dan keagamaan.

Dalam studi Yesa (2006) tentang konflik dan perdamaian terdapat gejala umum bahwa perempuan tidak ditempatkan sebagai aktor dalam pengambilan keputusan konflik ataupun perdamaian. Namun perempuan senantiasa menjadi pihak yang terdampak langsung dari pilihan keputusan konflik, meskipun mereka sebenarnya tidak banyak berkontribusi di dalamnya (Pattiasina et al., 2018). Sedangkan, studi Ismiati (2016) menunjukkan bahwa keterlibatan perempuan dalam pengambilan keputusan konflik dan perdamaian akan membuat pilihan keputusannya menjadi moderat.

Studi Cockburn (2013) menunjukan bahwa tidak dilibatkannya perempuan dalam keputusan konflik karena alasan psikologis, adat, atau alasan kapasitas. Alasan psikologis terkait dengan naluri perempuan yang cenderung mengedepankan rasa belas kasihan, solidaritas, dibandingkan dengan naluri laki-laki yang mengedepankan sikap untuk teguh pendirian, pentingnya harga diri dan kehormatan kelompok. Alasan adat terkait dengan posisi perempuan sebagai pihak yang mendukung di belakang layar, karena tidak patut perempuan turut serta dalam perdebatan konflik yang didominasi laki-laki (Sultana, 2012). Sedangkan alasan kapasitas terkait kurangnya kesempatan perempuan untuk terlibat dalam peristiwa konflik dan 
perdamaian. Kurangnya jumlah jam terbang menyebabkan horizon pengetahuan konflik dan perdamaian perempuan menjadi kurang (Lestari, 2017).

Dalam sejumlah konflik yang terjadi di lingkungan desa Kadirojo, keterlibatan perempuan tidak banyak dilibatkan dalam sejumlah rapat oleh pihak yang sedang berkonflik, termasuk dalam rapat perumusan penyelesaian konflik. Perempuan hanya berperan menyediakan sejumlah hidangan tatkala para pengurus takmir berembug, dan ketika diajak untuk memberikan sumbang saran, sejumlah perempuan hanya menyerahkan kepada keputusan yang dibuat oleh pengurus Takmir Masjid yang bergender laki-laki, karena dianggap lebih mumpuni dan berkapasitas dalam isu yang rumit.

Sebuah contoh konflik keagamaan yang terjadi di desa Kadirjo Palbapang Bantul adalah konflik terkait keinginan sebagian warga masyarakat untuk mengubah status musholla menjadi masjid. Pilihan perubahan status musholla ini mendapat penolakan dari takmir masjid Al-Fajar. Penolakan dilandasi argumen bahwa jarak masjid Al-Fajar dengan calon masjid baru adalah hanya $300 \mathrm{~m}$, tidak sesuai dengan kaidah fiqh tentang pendirian masjid. Dengan perubahan status tersebut, mau tidak mau masjid tersebut harus menyelenggarakan kegiatan keagamaan harian, mingguan ataupun bulanan secara mandiri. Inilah yang kemudian dijadikan argumen pokok bahwa hadirnya dua masjid dalam satu dusun justru akan melahirkan konflik yang tidak produktif.

Kasus kedua juga terkait dengan berdirinya masjid baru dalam satu dusun. Isu paling kritikalnya adanya rumor bahwa pembangunan masjid tersebut didanai oleh kalangan non muslim. Masyarakat kemudian terbelah menjadi dua, baik yang pro dan kontra. Pihak yang mendukung menyatakan bahwa masjid tersebut dibangun oleh keluarga muslim yang memiliki putra yang non muslim. Hakekatnya yang membangun tetap kaum muslimin. Yang kontra membangun argumen bahwa ada sejumlah keraguan atau syubhat, sehingga dikhawatirkan masjid tersebut akan menjadi titik masalah. Argumen yang dikeluarkan dengan mempergunakan surat at-Taubah ayat 107 tentang masjid Dhirar, sebuah masjid yang dibangun oleh sekelompok orang Yahudi yang dipergunakan untuk memecah belah umat Islam (Shaleh \& Dahlan, 2011).

Eskalasi konflik terkait dengan pendirian masjid tersebut berjalan dengan sangat serius, sehingga sejumlah pihak terlibat untuk menempatkan pokok masalah tersebut secara proporsional. Muhammadiyah mengambil jalan tengah dengan bersedia melakukan pengelolaan masjid tersebut secara proporsional demi kemaslakahatan bersama. Forum Kerukunan Umat Beragama juga turut melerai berkembangnya konflik tersebut agar tidak dimasuki oleh pihak luar yang justru akan memperumit penyelesaian konflik.

Dalam dua konflik di atas, perempuan dan aktivis Aisyiyah tidak banyak terlibat dalam pengambilan keputusan konflik maupun perdamaian. Kaum perempuan lebih berperan untuk menfasilitasi sejumlah rapat agar 
dapat berlangsung secara produktif. Tidak banyak hadirnya perempuan dan aktivis Aisyiyah dalam isu ini disebabkan oleh 3 realitas besar.

Pertama, kurangnya literasi tentang konflik dan resolusi. Kondisi ini sangat terkait dengan kurangnya pengajian yang membahas tema-tema konflik. Terdapat asusmi bahwa konflik dan resolusi bukan dunia bagi perempuan. Pengajian seakan tabu berbincang tentang konflik dan resolusi konflik, dan kemasan pelaksanaan pengajian di masyarakat cenderung dengan bahasa yang normatif putih. Kondisi ini menyebabkan perempuan seakan teralienasi dalam perbincangan yang cenderung sensitif dan tidak layak untuk diperbincangkan dalam komunitas perempuan.

Kedua, Dominannya kultur patriakhi dalam pengambilan keputusan di dalam masyarakat agraris (Sultana, 2012). Perempuan dalam kultur masyarakat agragris lebih berperan sebagai unit pendukung dibandingkan sebagai subyek sosial. Pilihan politik perempuan lebih banyak ditentukan oleh preferensi politik dari laki-laki. Dalam konteks studi budaya politik, pilihan politik perempuan cenderung mencerminkan budaya politik subyek. Sebuah tipologi budaya politik yang mengambarkan bahwa pilihan politik seseorang justru ditentukan oleh pilihan politik dari luar dirinya (Almond \& Verba, 2015).

Dominasi pengambilan keputusan terkait konflik dan perdamaian yang didasarkan oleh pertimbangan laki-laki menyebabkan suara perempuan sebagai gagasan alternatif menjadi kurang terdengar. Pilihan para perempuan yang cenderung bersifat tertutup dengan dirinya sendiri membuat kontribusi perempuan dalam proses resolusi menjadi bersifat reaksioner, pemadam kebakaran, setelah keputusan konflik dan perdamaian benar-benar terealisasi baru banyak perempuan menyesali pilihan tersebut.

Ketiga, kurang percaya dirinya kader Aisyiyah untuk berkontestasi gagasan dan berkontestasi dalam politik. Hal ini ditandai masih rendahnya kader Aisyiyah untuk mencalonkan diri sebagai pemimpin politik di tingkat dusun dan desa. Dalam sejarah politik di dusun Kadirojo, belum pernah ada kader Aisyiyah yang mencalonkan diri sebagai kandidat perangkat desa, ataupun kandidat anggota legislatif.

Artikel ini hendak melakukan transformasi pengetahuan, nilai, dan keberanian sosial bagi perempuan untuk melakukan proses mobilitas sosial baik vertikal dan horizontal. Mobilitas vertikal dalam makna perempuan berani untuk mengartikulasikan gagasan di forum terbuka tentang preferensi dan harapan perempuan dalam kehidupan sosial. Mobilitas horizontal, perempuan mendapatkan kesempatan untuk mengikuti kegiatan publik, bukan hanya terbatas kegiatan perempuan.

Untuk meningkatkan kapasitas tersebut, program pengabdian disusun dalam konsep literasi perdamaian. Gagasan ini berasal dari upaya untuk mengaktualkan kelebihan alamiah perempuan sebagai aktor perdamaian. Perempuan memiliki bakat terpendam yang unik dan bila dapat distimuli secara efektif akan melahirkan gagasan perdamaian yang luar biasa ( $F$. Hutabarat, 2017). Stimuli perdamaian dapat dilakukan dalam bentuk bermain 
peran, atau menjalankan peran sesuai dengan aturan main yang ditetapkan. Bermain peran dalam konteks Pendidikan memiliki pengaruh yang kuat terhadap proses penyerapan pengetahuan dan merefleksikan pengatahuan tersebut ke dalam tindakan (Çerkez et al., 2012).

Permainan peran yang dipilih adalah Hikayat Kerbau Air. Permainan ini disusun oleh Yasri Sulaiman, seorang motivator yang mendirikan Yayasan SPA Indonesia. Dalam permainan Hikayat Kerbau Air terdapat 5 pelaku utama. Pertama kelompok pemilik Kerbau Air, yakni Suku Ingungi, dan 2 kelompok yang berkepentingan terhadap Kerbau air, yakni Suku Abombo dan Dayak. Dua pelaku lainnya adalah Dukun, yang memberikan informasi bahwa kerbau air mengidap penyakit, yang dalam konteks permainan akan berperan sebagai provokator, dan pelaku terakhir adalah mediator, pihak ketiga yang memberikan ruang kepada para stakeholder konflik untuk bertemu guna merumuskan keputusan yang paling rasional. (Naskah Hikayat Kerbau Air akan disisipkan dalam Apendix).

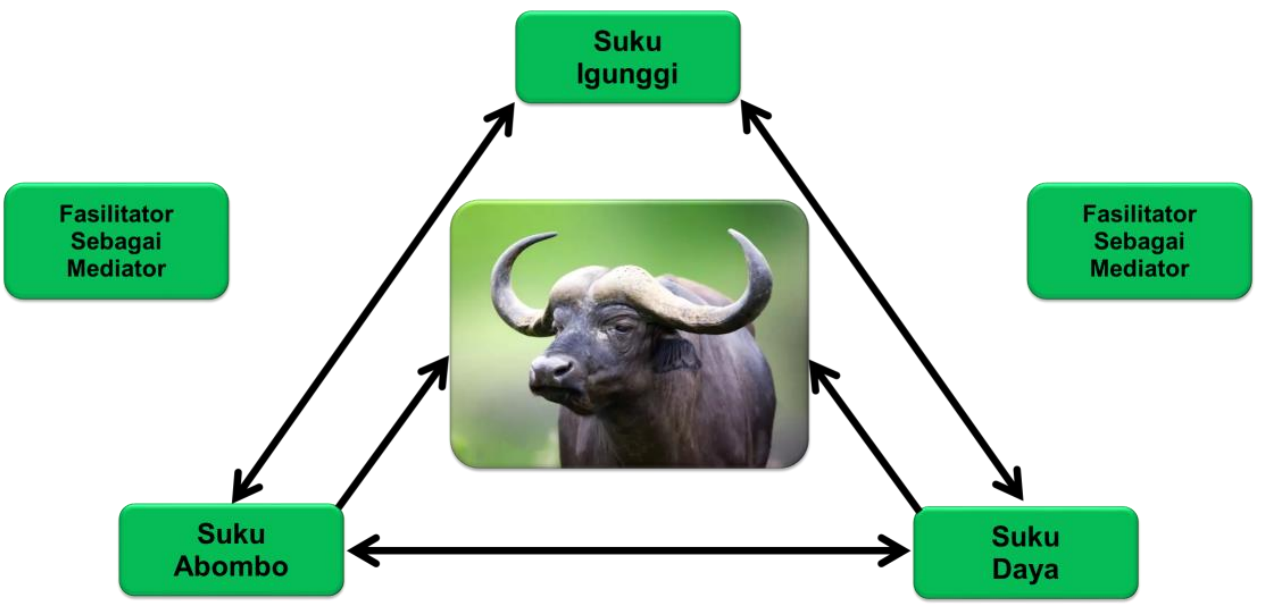

Gambar 1. Model Pemain Dalam Permainan

Dalam permainan tersebut dijalankan dalam 7 babak. Setiap peserta mendapatkan deposit kartu perang sebanyak 7 buah dan kartu damai sebanyak 7 buah. Masing-masing perserta memiliki otonomi untuk mengambil keputusan. Dalam setiap babak akan ditentukan estimasi penghitungan skor. Misal bila dalam pengambilan keputusan tersebut jatuh 2 kartu perang, dan satu kartu damai, maka yang menjatuhkan kartu perang dapat skor -1 , dan kartu damai dapat skor 3. (Aturan main dalam Permainan Hikayat Kerbau Air akan disisipkan dalam Appendix).

Aturan main akan diinformasikan kepada peserta per babaknya. Para peserta tidak pernah tahu kira-kira aturan main per babaknya seperti apa. Kondisi ini memaksa para pemain untuk fokus dan membaca aturan main dengan seksama. Setelah keputusan di ambil, maka fasilitator akan 
memberikan informasi, kartu yang dipilih apa saja, apakah kartu damai atau kartu perang, dan saat itulah skor diumumkan per babak.

Permainan dikelola dalam dua ranah. Ranah pertama para peserta berfikir secara inward looking, di mana para anggota suku akan berdiskusi dengan sesama anggota, dan mengestimasi pilihan yang akan dipilih oleh suku yang lain. Ranah ini akan dijalankan dari babak 1 sampai ke 3. Masuk pada babak ke 4, fasilitator memberikan kesempatan kepada perwakilan suku untuk berdiskusi pilihan apa yang kira-kira terbaik. Bagaimana dengan peran provokator? Provokator akan bermain di setiap babak dengan cara menghembuskan kabar-kabar palsu, menggoyang pilihan, ataupun membuat sesuatu menjadi tidak pasti. Peran fasilitator juga bermain di setiap babak, dan terkhusus akan bermain secara formal pada babak ke 4 dan ke 7 sebelum permainan usai.

Tabel 1. Contoh Aturan Main tentang Skor

\begin{tabular}{cc}
\hline $\begin{array}{c}\text { Tahap IV } \\
\text { (diadakan negosiasi dengan meminta } \\
\text { bantuan fasilitator) }\end{array}$ & Skoring \\
\hline 1 kartu damai, 2 kartu perang & Kartu damai dapat 3, kartu perang dapat -3 \\
1 kartu perang, 2 kartu damai & Kartu damai dapat -1 , dan perang dapat 3 \\
Semua kartu perang & Semua dapat -3 \\
Semua kartu damai & Semua dapat 1 \\
\hline
\end{tabular}

Filosofi dalam hikayat Kerbau Air adalah perebutan terhadap sumber daya yang terbatas oleh para pihak dengan besaran kepentingan yang berbeda-beda. Termasuk di dalamnya hadirnya pihak ke 3 yang mengambil keuntungan dari situasi konfliktual sebagai gejala yang alamiah, dan hadirnya pihak ke 3 yang menfasilitasi penyelesaian konflik. Hikayat ini juga mengajarkan bahwa konflik berlangsung secara alamiah, ada saatnya konflik muncul, kemudian mengalami ekskalasi, dan kemudian mengalami deeskalasi serta menuju ke arah integrasi dan reskonsiliasi (Acemoglu \& Wolitzky, 2014).

\section{METODE PELAKSANAAN}

Metode pelaksanaan pengabdian tercermin ke dalam gambar berikut: Pertama, mempersiapkan instrumen yang diperlukan baik intrumen fisik maupun non fisik serta perlengkapan yang dapat menunjang kondusifitas pelaksanaan pengabdian. Kedua, dilakukan asesmen untuk menentukan pola pengetahuan dan pengalaman dari konflik, yang kemudian dijadikan pertimbangan untuk pembagian kelompok dalam simulasi permainan. Ketiga, dilakukan intervensi melalui siraman spiritual sebelum FGD dan simulasi Hikayat Kerbau air dilakukan. Keempat, mengadakan diskusi dari pengalaman berstruktur dari permainan Hikayat Kerbau Air tentang definisi konflik, eskalasi konflik, gaya konflik dan alternatif resolusi konflik. Dan tahap terakhir 
dilakukan pengukuran ulang terkait dengan transformasi pengetahuan dan perilaku tentang konflik dan perdamaian.

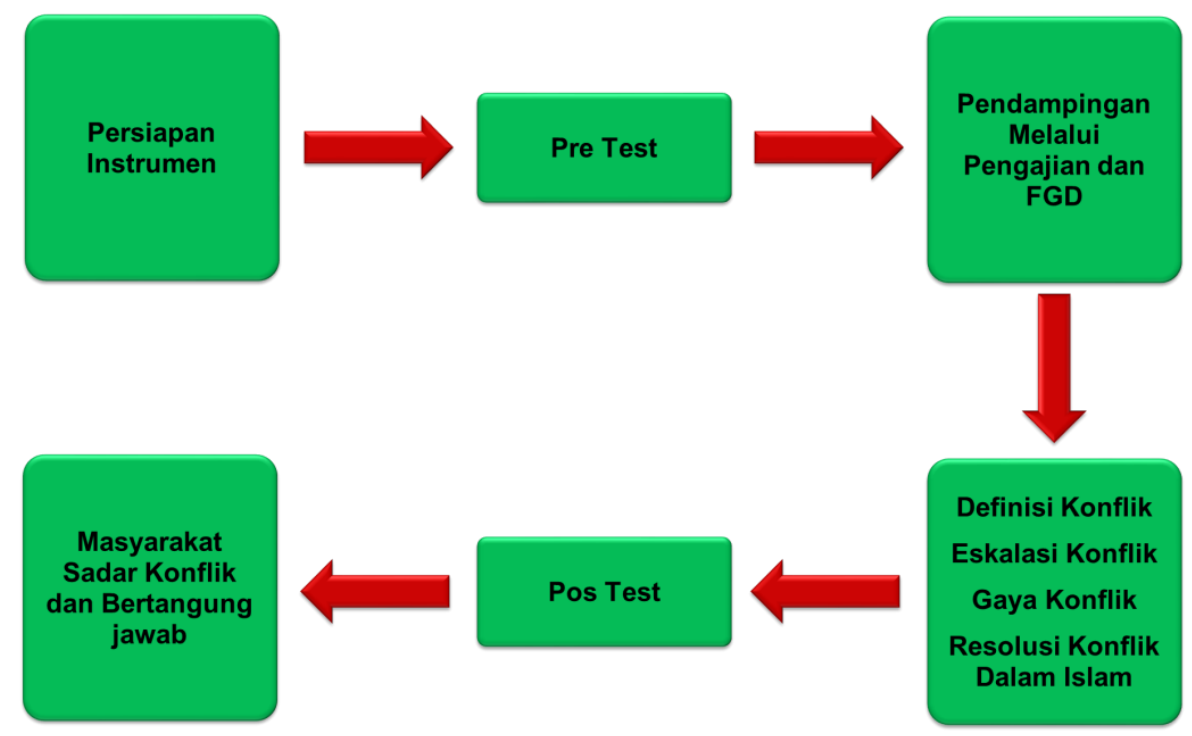

Gambar 2. Alur Pelaksanaan Pengabdian

\section{HASIL DAN PEMBAHASAN}

Pelaksanaan pengabdian pada masyarakat di lakukan di komplek masjid al-Fajar Kadirojo Palbapang Bantul, yang diikuti oleh 24 peserta yang terwakili dari beberapa golongan umum, baik aktivis Nasyiatul Aisyiyah dan dari aktivis Aisyiyah. Nasyiatul Aisyiyah merupakan organisasi otonom Muhammadiyah yang anggotanya adalah kalangan muda, dan biasanya belum menikah. Pelaksanaan pengabdian berlangsung selama 6 jam, diawali pada pukul 09.00 sampai dengan 15.00 WIB.

Permainan Hikayat Kerbau Air dimainkan setelah proses dan stimulasi gagasan sederhana dengan ukhuwah Islamiyyah dan tantangan umat Islam sebagai Rahmatan lil 'alamin. Permainan Hikayat Kerbau Air berlangsung selama 2 jam, dari babak pertama sampai Babak ke 7. Permainan Kerbau Air diawali dengan menampilkan cerita tentang Kerbau Air (Cerita Kerbau Air akan dilampirkan dalam Apendix). Dan kemudian proses pembagian kelompok menjadi 3 kelompok besar, yang akan mewakili suku Ingunggi sebagai pemilik Kerbau Air yang mengalami dilema, dan suku Dayak dan Abombo yang berminat untuk memiliki Kerbau Air demi kebutuhan kohesivitas kelompok. 


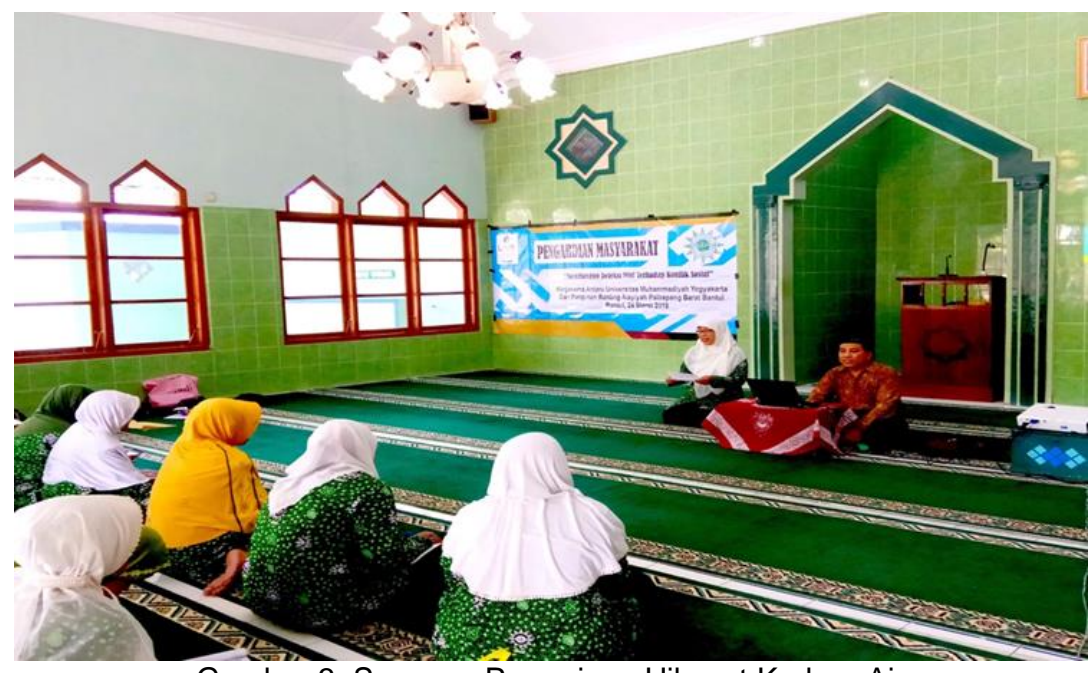

Gambar 3. Suasana Permainan Hikayat Kerbau Air

Kemudian fasiliator menyampaikan kisi-kisi dan aturan permainan termasuk dengan menampilkan aturan skor untuk per babak. Fasilitator juga mendistribusikan 7 kartu damai dan 7 kartu perang yang disimpan ke dalam amplop untuk masing-masing kelompok. Fasilitator juga menegaskan pentingnya menjaga kerahasiaan pilihan, dan memainkan permainan ini seakan-akan mewakili realitas sesungguhnya.

Tabel 2. Hasil Skoring Babak 1-4

\begin{tabular}{cccccccc}
\hline \multirow{2}{*}{ No } & \multirow{2}{*}{ Tahap } & \multicolumn{7}{c}{ NAMA SUKU } \\
\cline { 3 - 8 } & & Abombo & Skor & Igunggi & Skor & India & Skor \\
\hline 1 & Pertama & $\mathrm{P}$ & 2 & $\mathrm{P}$ & 2 & $\mathrm{D}$ & 1 \\
2 & Kedua & $\mathrm{P}$ & 1 & $\mathrm{D}$ & 2 & $\mathrm{D}$ & 2 \\
3 & Ketiga & $\mathrm{D}$ & 3 & $\mathrm{P}$ & -3 & $\mathrm{P}$ & -3 \\
4 & Keempat & $\mathrm{D}$ & -1 & $\mathrm{D}$ & -1 & $\mathrm{P}$ & 3 \\
\hline & Skor & & $\mathbf{5}$ & & $\mathbf{0}$ & & $\mathbf{3}$ \\
\hline
\end{tabular}

Pada 4 babak pertama, tercermin dinamika bahwa pemilik Kerbau Air yakni suku lgunggi mendapatkan skor paling rendah. Hal ini dapat dimengerti karena kedua suku yang memiliki minat terhadap Kerbau Air menempatkan suku lgunggi sebagai musuh bersama. Apalagi dalam konteks pilihan kartu suku lgunggi memainkan peran secara pragmatis, di mana dalam 4 babak suku lgunggi menjatuhkan kartu Perang dan Damai secara bergantian. Sangat berbeda dengan pihak suku Dayak dan Abombo yang cenderung lebih hati-hati dan konsisten untuk menjatuhkan pilihan.

Permainan pragmatis suku Igunggi sebagai pemilik sesungguhnya menunjukan efektivitas sampai babak ke 2, di mana skor suku lgunggi mendapatkan 4, sedangkan suku yang lain dapat 3. Namun pada babak ke tiga, pilihan suku Igunggi kurang taktis sehingga mendapatkan skor -3 . Yang 
lebih naik, suku Igunggi justru mendapatkan skor negatif kembali di babab ke 4, meski sudah dilakukan proses negosiasi.

Apa makna dari tahap ini? Skor menjadi sangat dinamis karena pragmatis dari ketiga suku bersama-sama berkeinginan memaksimalkan hasil. Pada saat itulah ruang dan peluang dari provokator masuk dengan menawarkan keuntungan dan harapan baru yang lebih besar (Denson et al., 2011). Kondisi ini menyebabkan pihak suku lgunggi sebagai pemilik Kerbau Air berharap mendapatkan skor yang berlipat di babak ke 3. Namun justru harapan tinggal harapan.

Lantas apakah hasil paruh babak tersebut sudah final? Ternyata unik, informasi dalam debrief melalui pengajian sebelum permainan dimulai menunjukan kinerja yang menarik. 3 babak berikutnya memunculkan hasil yang luar biasa. Terdapat sebuah kesadaran dari pihak yang membutuhkan Kerbau Air untuk tidak lagi menempatkan suku lgunggi sebagai musuh bersama. Adalah tidak etis pada perebutan asset Kerbau Air, pemilik justru tidak mendapatkan apa-apa. Apa makna, berarti kedua suku yang membutuhkan Kerbau Air melakukan aktivitas perampokan kepada pemilik Kerbau Air. Perilaku pengambilan keputusan dari Suku Abombo dan Dayak memberikan kesempatan kepada suku Igunggi untuk mendapatkan skor. Mari kita cermati tabel berikut.

Tabel 3. Hasil Skoring babak 5-7

\begin{tabular}{cccccccc}
\hline \multirow{2}{*}{ No } & Tahap & \multicolumn{7}{c}{ NAMA SUKU } \\
\cline { 3 - 7 } & & Abombo & Skor & Igunggi & Skor & India & Skor \\
\hline 1 & Pertama & $\mathrm{P}$ & 2 & $\mathrm{P}$ & 2 & $\mathrm{D}$ & 1 \\
2 & Kedua & $\mathrm{P}$ & 1 & $\mathrm{D}$ & 2 & $\mathrm{D}$ & 2 \\
3 & Ketiga & $\mathrm{D}$ & 3 & $\mathrm{P}$ & -3 & $\mathrm{P}$ & -3 \\
4 & Keempat & $\mathrm{D}$ & -1 & $\mathrm{D}$ & -1 & $\mathrm{P}$ & 3 \\
5 & Kelima & $\mathrm{D}$ & 1 & $\mathrm{P}$ & 2 & $\mathrm{P}$ & 2 \\
6 & Keenam & $\mathrm{D}$ & -4 & $\mathrm{D}$ & 4 & $\mathrm{P}$ & -4 \\
7 & Ketujuh & $\mathrm{D}$ & 2 & $\mathrm{P}$ & 2 & $\mathrm{P}$ & 2 \\
\hline & Skor & & $\mathbf{4}$ & & $\mathbf{8}$ & & $\mathbf{3}$ \\
\hline
\end{tabular}

Dari tabel 3 terlihat, Igunggi yang pada paruh pertama menjadi pihak losser justru di akhir babak menjadi pemenang. Yang juga menarik hasil akhir kesemua peserta mendapatkan skor + semuanya, dan tidak ada yang mendapatkan skor -. Dalam konteks game theory (Yasukawa, 2019), fenomena ini dikenal dengan istilah win win solution (Kabra, 2013) atau non zero sum game.

Mengapa bisa terjadi seperti ini? Inilah dinamika resolusi konflik dan perdamaian yang dapat dipelajari bersama dalam sebuah permainan interaktif. Kesediaan untuk berbagi menjadi kata kunci agar terjadi transformasi konflik yang sebelumnya berwatak zero sum game, di mana satu kelompok ingin menang secara sepihak yang berarti pihak lain harus kalah secara mutlak. Faktor lain yang juga menarik adalah tinggi intensitas pemain 
sebagai fasilitator perdamaian yang juga berkompetisi dengan provokator konflik. Semakin fasilitator perdamaian melakukan sosial engagement dengan memberikan alternatif yang dapat ditempuh agar tercapai kesepakatan secara baik, dan disusun secara rasional dan obyektif mampu mengiring pihak yang berkonflik untuk mengambil pilihan dari negosiator.

Hal ini tercermin dari babak ke 6, di mana pihak suku Abombo dan Dayak bersedia untuk mengalah, sehingga point kedua suku ini mendapatkan pengurangan secara signifikan yakni -4 untuk menolong kepada pemilik Kerbau Air untuk mendapatkan haknya secara proporsional. Pada babak ke 7, fasilitator perdamaian mampu mendorong agar tercapai integrasi dan rekonsiliasi, di mana ditandai dengan distribusi skor masing-masing suku mendapatkan 2.

Dari permainan Hikayat Kerbau Air ini, para peserta menjadi sangat mengerti apa yang dimaksud dengan konflik. Bagaimana ekspresi konflik. Fasilitator mengajukan sejumlah pertanyaan untuk mengidentifikasi babak per babak. Hampir semua peserta menjadi tahu apa ciri-ciri konflik mengalami eskalasi. Kapan kira-kira negosiasi layak untuk ditawarkan dan disepakati. Bagaimana bahaya menerima saran dan masukan dari kelompok provokator, dan bagaimana bermanfaatnya mendengarkan saran dari fasilitator.

Dari sejumlah pengalaman berstruktur dalam permainan Hikayat Kerbau Air, terdapat lompatan yang tinggi dari para partisipan dalam dalam hal pengetahuan tentang konflik dan perdamaian. Pengalaman dalam permainan juga mampu mengartikulasikan gaya berkonflik dari masingmasing individu, dan bagaimana mengerem gaya konflik agak tidak selalu menggunakan gaya contending (menyerang), adakala menggunakan gaya yielding (mengalah), adakalanya dengan gaya avoiding (menghindar), dan ada kalanya menggunakan gaya integrating (menyatukan).

Variasi penguasaan gaya konflik, negosiasi dalam membangun perdamaian memperkuat kepercayaan diri para aktivis Aisyiyah Dusun Kadirojo Palbapang Bantul untuk terlibat dalam sumbang fikir dalam isu sosial kemasyarakatan. Kesediaan ini berkontribusi positif terhadap semakin banyaknya aktivis Aisyiyah yang terlibat dalam kegiatan pendampingan keluarga sakinah dalam masyarakat.

\section{KESIMPULAN}

Internalisasi nilai kepada orang dewasa dan memiliki pengalaman dan kesadaran sosial yang tinggi memerlukan pendekatan yang khusus. Simulasi merupakan proses transfer pengetahuan dan nilai dengan menyentuh pemikiran bawah sadar partisipan cenderung mudah diterima. Ekspresi kegembiraan dan kesedihan dalam permainan simulasi mampu menstimuli lahirnya kesadaran baru bahwa meskipun hidup penuh dengan kompetisi dan konflik, penuh dengan narasi kemenangan dan kekalahan diperlukan sikap emphati dan simpati. Hidup bermasyarakat tidak bisa dilakukan hari ini saja, namun hidup bermasyarakat adalah hidup yang berkesinambunga. 
Pengabdian masyarakat kepada aktivis Aisyiyah memberikan makna baru bahwa bermasyarakat di era yang kompetisi yang ketat dan bebas memerlukan nilai untuk tetap simpati dan emphati sebagai pilar terakhir untuk membangun harmoni sosial.

\section{UCAPAN TERIMA KASIH}

Ucapan terima kasih kepada LP3M UMY yang telah memberikan pendanaan dalam pelaksanaan pengabdian, juga kepada pengurus dan aktivis Pimpinan Ranting Aisyiyah Palbapang Barat yang telah berpartisipasi. Kepada dr. Novarina yang telah menjadi narahubung dalam pengkoordinasian dan pelaksanaan pengabdian pada masyarakat.

\section{DAFTAR RUJUKAN}

Acemoglu, D., \& Wolitzky, A. (2014). Cycles of conflict: An economic model. American Economic Review, 104(4), 50-67. https://doi.org/10.1257/aer.104.4.1350

Almond, G. A., \& Verba, S. (2015). The civic culture: Political attitudes and democracy in five nations. Princeton University Press. https://www.jstor.org/stable/j.ctt183pnr2

Çerkez, Y., Altinay, Z., Altinay, F., \& Bashirova, E. (2012). Drama and Role Playing in Teaching Practice: The Role of Group Works. Journal of Education and Learning, 1(2), 109-120. https://doi.org/10.5539/jel.v1n2p109

Cockburn, C. (2013). War and security, women and gender: An overview of the issues. Gender and Development, 21(3), 433-452. https://doi.org/10.1080/13552074.2013.846632

Denson, T. F., Pedersen, W. C., Friese, M., Hahm, A., \& Roberts, L. (2011). Understanding impulsive aggression: Angry rumination and reduced self-control capacity are mechanisms underlying the provocationaggression relationship. Personality and Social Psychology Bulletin, 37(6), 850-862. https://doi.org/10.1177/0146167211401420

F. Hutabarat, L. (2017). Peningkatan Female Peacekeepers Indonesia Dalam Misi Pemeliharaan Perdamaian PBB. Jurnal Pertahanan \& Bela Negara, 7(2), 67-84. https://doi.org/10.33172/jpbh.v7i2.180

Ismiati. (2016). Eksistensi aktivis perempuan dalam mewujudkan Perdamaian di Aceh. Jurnal Al-Bayan, 22(33), 1-16. https://doi.org/10.22373/albayan.v22i33.643

Kabra, A. (2013). Conservation-induced Displacement: The Anatomy of a Win-Win Solution. Social Change, 43(4), 533-550. https://doi.org/10.1177/0049085713502592

Lestari, Y. S. (2017). Gender dan Pembangunan Perempuan di Aceh Pasca Konfik dan Tsunami: Pembahasan Teoretis. Community, 3(1), 59-73. https://doi.org/10.1017/CBO9781107415324.004

Pattiasina, S. M. O., Lattu, I. Y. M., \& Nuban Timo, E. I. (2018). Perempuan 
dan Liminalitas Perdamaian: Hubungan Islam-Kristen dalam Liminalitas Simbolik Kain Gandong di Maluku. PALASTREN Jurnal Studi Gender, 11(2), 205-232. https://doi.org/10.21043/palastren.v11i2.3298

Shaleh, K. H. Q., \& Dahlan, H. A. A. (2011). Asbabun Nuzul Latar Belakang Historis Turunya Ayat-ayat al-Quran (2nd ed.). Diponegoro.

Sultana, A. (2012). Patriarchy and Women's Subordination: A Theoretical Analysis. Arts Faculty Journal, 4 , $1-18$. https://doi.org/10.3329/afj.v4i0.12929

Yasukawa, K. (2019). Game theory. In Encyclopedia of Animal Behavior (pp. 45-50). https://doi.org/10.1016/B978-0-08-045337-8.00355-7

Yesa, L. (2006). Pengalaman perempuan dalam upaya memperjuangkan perdamaian di wilayah konflik : penelitian terhadap perempuan anggota gerakan perempuan peduli di Ambon [Universitas Indonesia]. http://lib.ui.ac.id/opac/ui/detail.jsp?id=95009\&lokasi=lokal 